\title{
Dielectric Relaxation Studies of Triethanolamine with 2-Alkoxyethanol using time Domain Reflectometry Technique
}

\author{
S. Kumar ${ }^{1 *}$, R. Amalanathan ${ }^{2}$ \\ ${ }^{1,2 a}$ Department of Physics, Annamalai University, Annamalainagar-608002, Tamilnadu, India \\ *Corresponding author: drskumar1962@gmail.com
}

Available online at: www.isroset.org

Received: 22/Jan/2019, Accepted: 14/Feb/2019, Online: 28/Feb/2019

\begin{abstract}
The dielectric relaxation studies of Triethanolamine with 2-Alkoxyethanols binary liquid mixtures have been determined over the frequency range of $10 \mathrm{MHz}$ to $20 \mathrm{GHz}$ at different concentrations using Time Domain Reflectometer (TDR) Technique at $303.15 \mathrm{~K}$. The dielectric permittivity $\left(\varepsilon^{\prime}\right)$ and dielectric loss $\left(\varepsilon^{\prime \prime}\right)$ has been plotted in the dielectric complex plane. The static dielectric constant $\left(\varepsilon_{0}\right)$, dielectric constant at high frequency $\left(\varepsilon_{\infty}\right)$, and relaxation time $(\tau)$ values are calculated. Using these parameters, the values of Bruggeman factor $\left(\mathrm{f}_{\mathrm{B}}\right)$, excess dielectric constant $\left(\varepsilon^{\mathrm{E}}\right)$ and excess inverse relaxation time $(1 / \tau)^{\mathrm{E}}$ were also calculated. The effective Kirkwood correlation factor $\left(\mathrm{g}^{\text {eff }}\right)$ and corrective Kirkwood correlation factor $\left(\mathrm{g}_{\mathrm{f}}\right)$ have also been determined and discussed to yield information on the structure and dynamics of the mixtures. The long range and short range interaction between the dipoles can be studied from the thermodynamic parameter, excess Helmholtz free energy $\left(\Delta \mathrm{F}^{\mathrm{E}}\right)$. The free energy of activation for relaxation time $(\Delta \mathrm{F} \tau)$ were also calculated and interpreted on the basis of nature of molecular interaction.
\end{abstract}

Keywords: Dielectric permittivity, Dielectric loss, Relaxation time, Time Domain Reflectometer, Triethanolamine, 2Alkoxyethanols, FTIR.

\section{INTRODUCTION}

Time Domain Reflectometry Technique is the powerful tool to identify the inter- and intra-molecular interactions of the liquid and liquid mixtures. Dielectric studies on mixtures of polar liquids either in the pure state or in the inert solvents have been a subject of interest because they provide useful information regarding molecular complex formation in solution and the structural changes in liquids due to changes in hydrogen bonding [1-5].The relative changes in dielectric parameters are important to predict structural changes in liquid. Studies of dielectric behavior of polar mixtures at different concentration and temperatures have led to valuable information regarding hydrogen bonding and solute-solvent interaction [6-11].

Triethanolamine (TEA) is highly polar liquid. Scrutiny of the effect of the $\mathrm{OH}$ and $\mathrm{NH}_{2}$ group of dielectric properties may provide new information concerning the nature of dielectric polarization and relaxation, since the hydrogen - bonding force of $\mathrm{OH}-\mathrm{H}$ bonding is generally accepted to the stronger than that of $\mathrm{NH}-\mathrm{N}$ bonding. Triethanolamine molecules have the combined physical and chemical properties of both the alcohols and TEA. Hence it is interesting to study the H- bond interaction of Triethanolamine with 2-Alkoxyethanol mixtures over the entire concentration range by dielectric constant measurements.

Triethanolamine (TEA) is a multifunctional substance that is capable of hydrogen bonding by both donation and acceptance of hydrogen bonds. The present work is a study of the dielectric behavior and molecular interactions between Triethanolamine with 2-Alkoxyethanols like 2-Methoxyethanol, 2-Ethoxyethanol and 2-Butoxyethanol at different concentrations. Dielectric complex permittivity's of these systems were found over the frequency range 10MHZ to $20 \mathrm{GHZ}$ at 303.15K. by employing TDR measurements.

Dielectric relaxation spectroscopy provide the response of solution to an applied electric field in terms of complex permittivity $\varepsilon^{*}=\varepsilon^{\prime}-\mathrm{j} \varepsilon^{\prime \prime}$, where $\varepsilon^{\prime}$ in the dielectric permittivity or the ability of medium to absorb microwave energy and $\varepsilon^{\prime \prime}$ in the dielectric loss or the ability of medium to conversion of absorbed microwave energy to heat [12]. Time domain reflectometry 
method has proven to be a powerful tool for investigating the dielectric relaxation properties and molecular dynamics process of the solvent. This method covers a broad range of frequency in a single measurement [13].

\section{EXPERIMENTAL}

\subsection{Materials}

AR grade chemical such as Triethanolamine, 2-Methoxyethanol (2-ME), 2-Ethoxyethanol (2-EE) and 2Butoxyethanol (2-BE) were obtained commercially and were used without further purification. The solutions were prepared at different volume percentages from $0 \%$ to $100 \%$ in step of $20 \%$ at $303.15 \mathrm{~K}$.

\subsection{Methods}

Frequency and temperature dependent complex dielectric spectra for the pure liquids and their binary mixtures were measured using an Agilent infiniium DCA-J86100A Time Domain Reflectrometer with a sample oscilloscope (HP model 54754A). Step voltage pulse of 39 Ps rise time were generated using a tunnel diode and fed through the transmission line of 50 $\Omega$ impedance semi rigid coaxial cable of pin length $0.135 \mathrm{~mm}$. The end of the rigid coaxial probe was dipped into the sample cell. The temperature was maintained by a water circulation temperature controller unit with an accuracy of $0.5 \mathrm{~K}$.

The variation of the step pulse was monitored from its reflection from air and sample using a simple oscilloscope and recorded at a time window of 2 ns. Reflected pulses were digitized into 1024 points and were used for further data analysis. All the measurements were carried out in an open load condition. Using the reflection coefficient spectra, the frequency dependent complex dielectric spectra were obtained [14]. The refractive indices of the pure and binary liquid mixtures under investigation were measured using an Abbe's refractometer at $303.15 \mathrm{~K}$. The dielectric constant at infinite dilution $\left(\varepsilon_{\infty}\right)$ has been calculated by using the following relation $\left(\varepsilon_{\infty}=\mathrm{n}_{\mathrm{D}}^{2}\right)$.

\section{RESULTS AND DISCUSSION}

The polar-polar binary liquid mixture systems taken for the study of molecular interactions here are

1) Triethanolamine +2 -Methoxyethanol

2) Triethanolamine +2 -Ethoxyethanol

3) Triethanolamine + 2-Butoxyethanol

Table 1: Experimental Densities $(\rho)$ and Refractive Indices $\left(n_{D}\right)$ values of Pure liquids along with the Literature values at $303.15 \mathrm{~K}$

\begin{tabular}{|c|c|c|c|c|c|c|c|c|}
\hline \multicolumn{7}{|c|}{ Liquids } \\
\hline Properties & \multicolumn{2}{|c|}{ Triethanolamine } & 2-Methoxyethanol & \multicolumn{2}{|c|}{ 2-Ethoxyethanol } & \multicolumn{2}{c|}{ 2-Butoxyethanol } \\
\hline & Exp. & Lit. & Exp. & Lit. & Exp. & Lit. & Exp. & Lit. \\
\hline $\boldsymbol{\rho}\left({\left.\mathbf{g} \cdot \mathbf{c m}^{-3}\right)}^{1.1180}\right.$ & $1.1185^{15}$ & 0.9557 & $0.9558^{17}$ & 0.9209 & $0.9212^{17}$ & 0.8926 & $0.8923^{17}$ \\
\hline $\mathbf{n}_{\mathbf{D}}$ & 1.7039 & $1.7233^{16}$ & 1.4028 & $1.3983^{17}$ & 1.4096 & $1.4065^{17}$ & 1.4209 & $1.4150^{17}$ \\
\hline
\end{tabular}

Table-2: Dielectric constant $\left(\varepsilon_{0}\right)$ and Relaxation time $(\tau)$ values of pure liquids along with literature values.

\begin{tabular}{l|c|c|c|cc}
\hline \multicolumn{2}{c}{ Liquids } & \multicolumn{2}{c}{} & & $(\boldsymbol{\tau})$ \\
& & & & Ps \\
\hline & Exp & Lit & Exp & \multicolumn{2}{c}{ Lit } \\
\hline Triethanolamine & 28.51 & $28.09^{16}$ & 397.20 & $383.19^{16}$ \\
\hline
\end{tabular}




\begin{tabular}{|l|l|l|l|l|}
\hline 2-Methoxyethanl & 16.76 & $16.54^{18}$ & 27.79 & $30.05^{19}$ \\
\hline 2-Ethoxyethanol & 15.91 & $16.45^{20}$ & 40.24 & $40.43^{20}$ \\
\hline 2-Butoxyethanol & 08.86 & $08.88^{21}$ & 52.61 & $49.18^{21}$ \\
\hline
\end{tabular}

\subsection{Dielectric permittivity $\left(\varepsilon^{\prime}\right)$}

The complex Dielectric permittivity spectra of two pure liquids as well as the three binary mixtures of Triethanolamine (TEA) with 2-Methoxyethanol (2-ME), 2-Ethoxyethanol (2-EE) and 2-Butoxyethanol (2-BE) are shown in figs.1 (a), 2(a) and 3(a). In the case of with 2-Alkoxyethanols systems, a graph is drawn between dielectric permittivity ( $\left.\varepsilon^{\prime}\right)$ on the $\mathrm{Y}$-axis and $\log \mathrm{F}$ on the $\mathrm{X}$-axis. From the graph it is inferred that the dielectric permittivity $\left(\varepsilon^{\prime}\right)$ is frequency dependent and comparatively high for TEA and is low for 2-Alkoxyethanols. As the concentration of TEA increases, the dielectric permittivity $\left(\varepsilon^{\prime}\right)$ values are also gets increases. In other words as the concentration of 2-Alkoxyethanols increases the dielectric permittivity $\left(\varepsilon^{\prime}\right)$ values gets decreases. Hence $\left(\varepsilon^{\prime}\right)$ values are directly proportional to the TEA concentrations and inversely proportional to the 2-Alkoxyethanols concentration [22].

\subsection{Dielectric loss $\left(\varepsilon^{\prime \prime}\right)$}

Similarly a graph is drawn between dielectric loss ( $\left.\varepsilon^{\prime \prime}\right)$ on $\mathrm{Y}$-axis and Log F on $\mathrm{X}$-axis and is shown in figs. 1(b), 2(b) and 3(b). The position of the peak of the curves shifts towards higher side (right) of Log F. As the Log F increases the dielectric loss $\left(\varepsilon^{\prime \prime}\right)$ also increases and then gradually decreases [23].

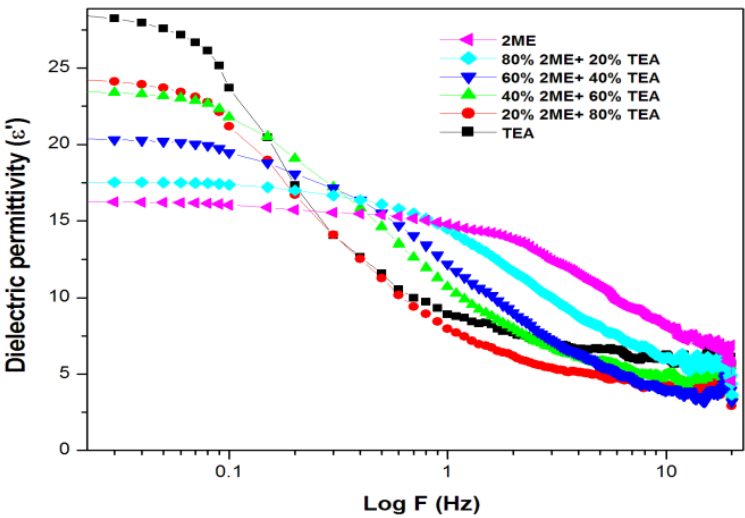

Fig 1: (a) Dielectric permittivity spectra vs. Log F (HZ) of Triethanolamine with 2-Methoxyethanol

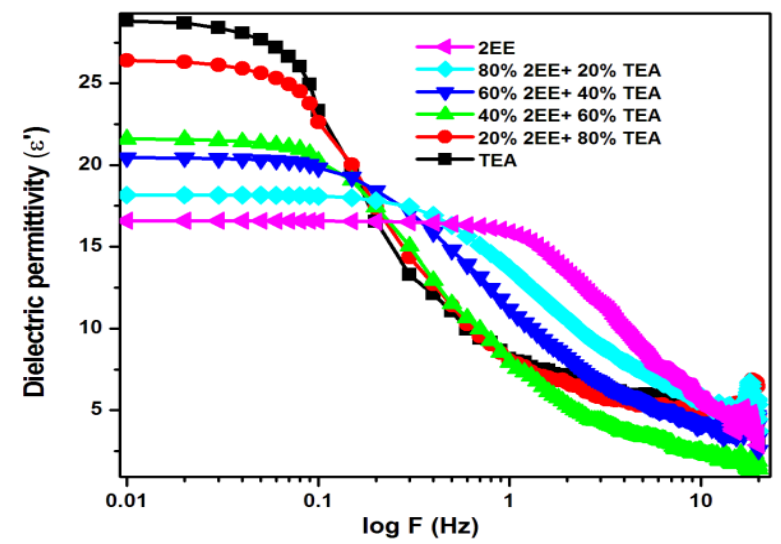

Fig 2: (a) Dielectric permittivity spectra vs. Log F (HZ) of Triethanolamine with 2-Ethoxyethanol

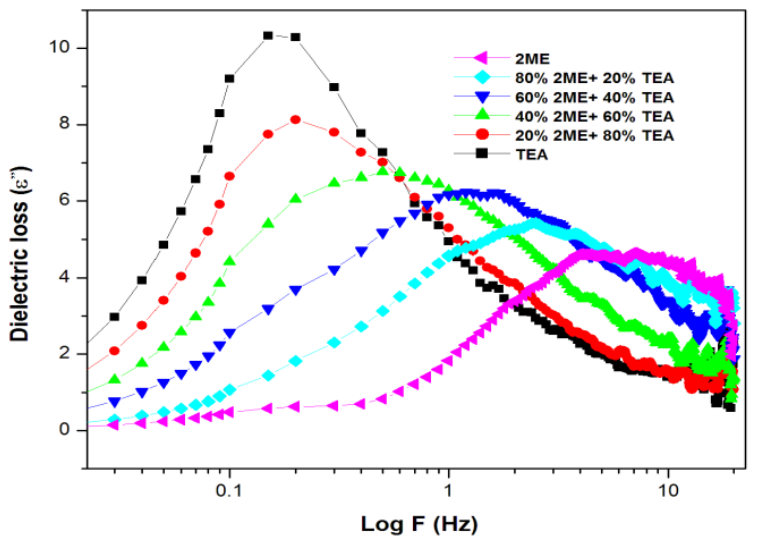

Fig 1: (b) Dielectric loss spectra vs. Log F (HZ) of Triethanolamine with 2-Methoxyethanol

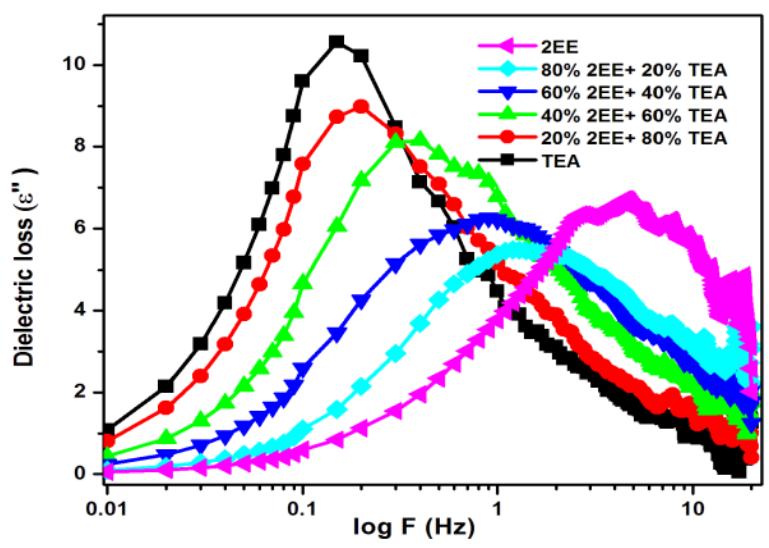

Fig 2: (b) Dielectric loss spectra vs. Log F (HZ) of Triethanolamine with 2-Ethoxyethanol 


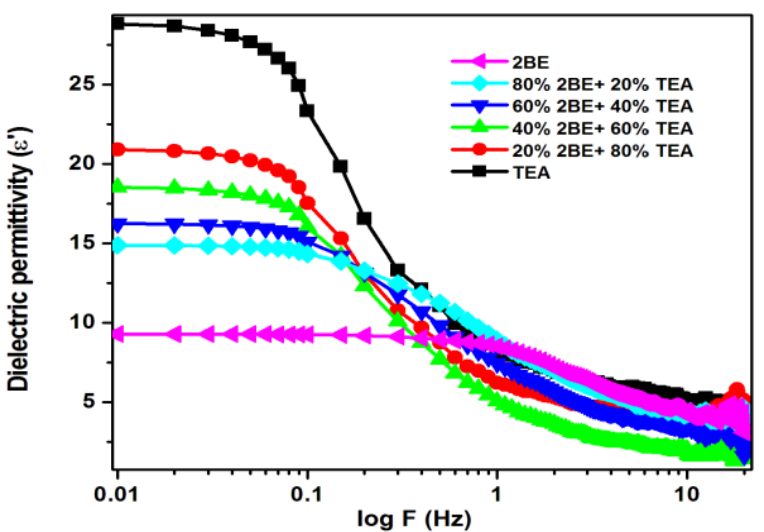

Fig 3: (a) Dielectric permittivity spectra vs. Log F (HZ) of Triethanolamine with 2-Butoxyethanol

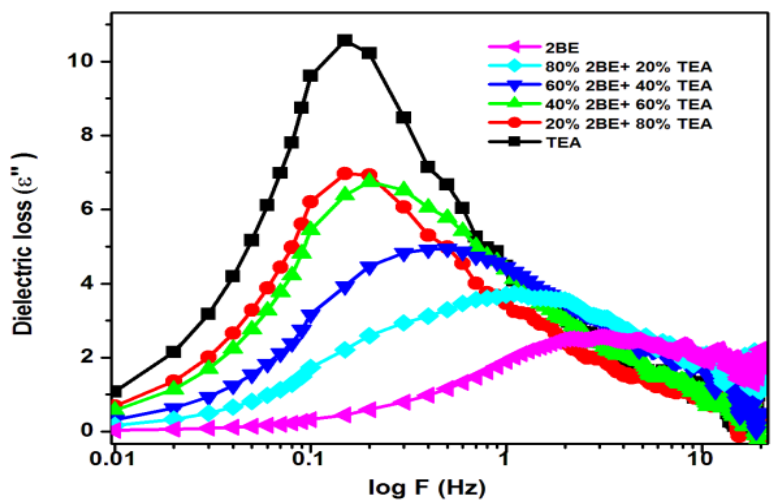

Fig 3: (b) Dielectric loss spectra vs. Log F (HZ) of Triethanolamine with 2-Butoxyethanol

\subsection{Dielectric constant $\left(\varepsilon_{\mathrm{o}}\right)$}

The Experimental static dielectric constant values of TEA is (28.51), 2-ME is (16.76), 2-EE is (15.91) and 2-BE is (8.86) and are listed in Table (2). In the case of TEA with 2-ME, $2-\mathrm{EE}$ and $2-\mathrm{BE}$ systems, as the volume percent of TEA increases the static dielectric constant $\left(\varepsilon_{\mathrm{o}}\right)$ values also gets increases [24-25].

\subsection{Dielectric constant at an optical frequency $\left(\varepsilon_{\infty}\right)$}

Table (3) shows that as the volume percent of the TEA molecule increases, the dielectric constant at an optical frequency $\left(\varepsilon_{\infty}\right)$ values are also gets increases for TEA with 2-ME, 2-EE and 2-BE systems. In other words, as the concentration of 2-Alkoxyethanol increases the dielectric constant at an optical frequency $\left(\varepsilon_{\infty}\right)$ values decreases.

\subsection{Relaxation time $(\tau)$}

In the pure state, the experimental relaxation time values of TEA is (397.20 Ps), 2-ME is (27.79 Ps), 2-EE is (40.24 Ps) and 2-BE is (49.18 Ps) and are listed in Table (3). The relaxation time depends critically on the nature of functional groups and volume of molecule. In our system, the relaxation time of pure 2-ME value is low and pure 2-BE is high. The relaxation time value of 2-EE is obtained between 2-ME and 2-BE. In addition, the relaxation time increases at increasing volume percent of DEA. This result shows that the relaxation time values may be due to the change in the molecular volume or change in the effective length of the dipole involved in the orientation process the relaxation time value depends mainly on the chain length of the molecule for the studies [26].

\subsection{Free energy of Activation for relaxation time $\left(\Delta \mathbf{F}_{\tau}\right)$}

$$
\text { RT } 2.303 \log _{10}\left[\frac{\tau_{\mathrm{o}} \mathbf{K T}}{h}\right] \ldots \ldots \ldots \text { (1) }
$$

The study of thermodynamic properties like free energy of activation for dielectric relaxation $\left(\Delta \mathrm{F}_{\tau}\right)$ for polar liquids may be useful in according with the states of dipoles under the influence of applied field. The measurement of free energy of activation for dielectric relaxation $\left(\Delta \mathrm{F}_{\tau}\right)$ is calculated for all the systems studied. The values are given in the Table (3). As the concentration of Triethanolamine increases, the free energy of activation for relaxation time $\left(\Delta \mathrm{F}_{\tau}\right)$ values gets increases. In other words as the concentration of $2-\mathrm{Alkoxyethanols}$ increases the free energy of activation for relaxation time $\left(\Delta \mathrm{F}_{\tau}\right)$ values get decreases. Hence $\left(\Delta \mathrm{F}_{\tau}\right)$ values are directly proportional to the TEA concentrations and inversely proportional to the 2-Alkoxyethanols concentration. It is clear from the $\left(\Delta \mathrm{F}_{\tau}\right)$ values of Triethanolamine (TEA) with 2-Alkoxyethanols systems that the relaxation time involves rotational motion only and not due to translational motion, The $\left(\Delta \mathrm{F}_{\tau}\right)$ is in the order of $2-\mathrm{ME}<$ $2-\mathrm{EE}<2-\mathrm{BE}[27]$. 
Table: 3. Values of static dielectric constant $\left(\varepsilon_{0}\right)$, dielectric constant at an optical frequency $\left(\varepsilon_{\infty}\right)$, relaxation time $(\tau)$ and free energy of activation for relaxation time $\left(\Delta \mathbf{F}_{\tau}\right)$ with volume fraction of Triethanolamine $\left(\phi_{2}\right)$ with 2-Alkoxyethanols.

\begin{tabular}{|c|c|c|c|c|}
\hline$\phi_{2}$ & $\varepsilon_{0}$ & $\boldsymbol{\varepsilon}_{\infty}$ & $\begin{array}{c}\tau \\
\text { Ps }\end{array}$ & $\begin{array}{c}\Delta \mathbf{F}_{\tau} \\
\mathbf{K J} / \mathbf{m o l}\end{array}$ \\
\hline \multicolumn{5}{|c|}{ System I: Triethanolamine+2-Methoxyethanol } \\
\hline $\mathbf{0}$ & 16.76 & 1.968 & 27.79 & 123.24 \\
\hline 0.2 & 17.31 & 2.086 & 78.73 & 125.87 \\
\hline 0.4 & 19.55 & 2.124 & 165.72 & 127.74 \\
\hline 0.6 & 21.97 & 2.164 & 303.10 & 129.26 \\
\hline 0.8 & 24.93 & 2.190 & 359.01 & 129.69 \\
\hline 1.0 & 28.51 & 2.202 & 397.20 & 130.01 \\
\hline \multicolumn{5}{|c|}{ System II: Triethanolamine +2-Ethoxyethanol } \\
\hline $\mathbf{0}$ & 15.91 & 1.990 & 40.24 & 124.11 \\
\hline 0.2 & 17.77 & 2.047 & 96.05 & 126.37 \\
\hline 0.4 & 19.54 & 2.077 & 163.28 & 127.71 \\
\hline 0.6 & 23.87 & 2.121 & 268.37 & 128.96 \\
\hline 0.8 & 25.73 & 2.166 & 329.01 & 129.69 \\
\hline 1.0 & 28.51 & 2.202 & 397.20 & 130.01 \\
\hline \multicolumn{5}{|c|}{ System III: Triethanolamine +2 -Butoxyethanol } \\
\hline $\mathbf{0}$ & 8.86 & 2.019 & 49.18 & 124.39 \\
\hline 0.2 & 13.28 & 2.063 & 102.14 & 126.52 \\
\hline 0.4 & 14.88 & 2.093 & 180.5 & 127.96 \\
\hline 0.6 & 17.68 & 2.157 & 290.56 & 129.16 \\
\hline 0.8 & 20.27 & 2.163 & 319.01 & 129.69 \\
\hline 1.0 & 28.51 & 2.202 & 397.20 & 130.01 \\
\hline
\end{tabular}

Table: 4. Values of Kirkood correlation factors $\left(g^{\text {eff }}, g_{f}\right)$, Bruggeman factor $\left(f_{B}\right)$, Excess dielectric constant $\left(\varepsilon^{E}\right)$ and excess inverse relaxation time $(1 / \tau)^{\mathrm{E}}$ with volume fraction of Triethanolamine $\left(\phi_{2}\right)$ with 2-Alkoxyethanols.

\begin{tabular}{|c|c|c|c|c|c|}
\hline$\phi_{2}$ & $\mathbf{g}^{\text {eff }}$ & $\mathbf{g}_{\mathbf{f}}$ & $\mathbf{f}_{\mathbf{B}}$ & $\varepsilon^{\mathrm{E}}$ & $(1 / \tau)^{E}$ \\
\hline \multicolumn{6}{|c|}{ System I: Triethanolamine +2-Methoxyethanol } \\
\hline $\mathbf{0}$ & 1.415 & 1.000 & 1.000 & 0.000 & 0.000 \\
\hline 0.2 & 1.283 & 0.874 & 0.942 & -1.871 & -0.017 \\
\hline 0.4 & 1.343 & 0.888 & 0.724 & -1.972 & -0.016 \\
\hline 0.6 & 1.403 & 0.903 & 0.508 & -1.895 & -0.012 \\
\hline 0.8 & 1.495 & 0.941 & 0.266 & -1.264 & -0.006 \\
\hline 1.0 & 1.620 & 1.000 & 0.000 & 0.000 & 0.000 \\
\hline \multicolumn{6}{|c|}{ System II: Triethanolamine +2-Ethoxyethanol } \\
\hline $\mathbf{0}$ & 2.088 & 1.000 & 1.000 & 0.000 & 0.000 \\
\hline 0.2 & 1.856 & 0.964 & 0.821 & 0.125 & -0.009 \\
\hline 0.4 & 1.781 & 0.940 & 0.664 & 0.807 & -0.008 \\
\hline 0.6 & 1.705 & 1.029 & 0.321 & 0.796 & -0.007 \\
\hline 0.8 & 1.658 & 1.002 & 0.188 & 0.066 & -0.004 \\
\hline
\end{tabular}




\begin{tabular}{|c|c|c|c|c|c|}
\hline $\mathbf{1 . 0}$ & 1.620 & 1.000 & 0.000 & 0.000 & 0.000 \\
\hline \multicolumn{6}{|c|}{ System II: Triethanolamine +2-Butoxyethanol } \\
\hline $\mathbf{0}$ & 1.613 & 1.000 & 1.000 & 0.000 & 0.000 \\
\hline $\mathbf{0 . 2}$ & 1.570 & 1.013 & 0.720 & -0.077 & -0.007 \\
\hline $\mathbf{0 . 4}$ & 1.410 & 0.879 & 0.620 & -2.261 & -0.008 \\
\hline $\mathbf{0 . 6}$ & 1.352 & 0.839 & 0.465 & -3.278 & -0.006 \\
\hline $\mathbf{0 . 8}$ & 1.326 & 0.820 & 0.338 & -4.448 & -0.003 \\
\hline $\mathbf{1 . 0}$ & 1.620 & 1.000 & 0.000 & 0.000 & 0.000 \\
\hline
\end{tabular}

Table: 5. Redlich-Kister coefficient and standard deviation values for excess parameters $\quad\left(\varepsilon^{\mathrm{E}}\right)$ and $(1 / \tau)^{\mathrm{E}}$ at $303.15 \mathrm{~K}$.

\begin{tabular}{|c|c|c|c|c|c|}
\hline Parameters & Systems & $\mathbf{A}_{0}$ & $\mathbf{A}_{1}$ & $\mathbf{A}_{2}$ & $\boldsymbol{\sigma}$ \\
\hline & $\mathrm{TEA}+2 \mathrm{ME}$ & -7.8386 & -2.6895 & -5.4394 & 0.0827 \\
\hline \multirow[t]{3}{*}{$\left(\varepsilon^{E}\right)$} & $\mathrm{TEA}+2 \mathrm{EE}$ & 3.6824 & 0.2687 & -8.5709 & 0.0067 \\
\hline & $\mathrm{TEA}+2 \mathrm{BE}$ & -11.2145 & 20.3312 & -8.1282 & 0.4266 \\
\hline & $\mathrm{TEA}+2 \mathrm{ME}$ & -0.0289 & -0.0208 & -0.0065 & 0.0004 \\
\hline \multirow[t]{2}{*}{$(1 / \tau)^{E}$} & $\mathrm{TEA}+2 \mathrm{EE}$ & -0.0300 & -0.0229 & -0.0292 & 0.0005 \\
\hline & $\mathrm{TEA}+2 \mathrm{BE}$ & -0.0289 & -0.0208 & -0.0065 & 0.0003 \\
\hline
\end{tabular}

Table: 6. Values of excess Helmholtz free energy $\left(\Delta \mathbf{F}^{\mathrm{E}}\right)$ and its components with volume fraction of Triethanolamine $\left(\phi_{2}\right)$ with 2-Alkoxyethanols.

\begin{tabular}{|c|c|c|c|c|}
\hline$\phi_{2}$ & $\begin{array}{l}\Delta \mathbf{F}_{\mathbf{0 r}}{ }^{\mathrm{E}} \\
\mathbf{J} / \mathbf{m o l}\end{array}$ & $\begin{array}{l}\Delta \mathbf{F}_{\mathbf{r r}}^{\mathrm{E}} \\
\mathbf{J} / \mathbf{m o l}\end{array}$ & $\begin{array}{l}\Delta \mathbf{F}_{12}{ }^{\mathrm{E}} \\
\mathrm{J} / \mathbf{m o l}\end{array}$ & $\begin{array}{c}\Delta \mathbf{F}^{\mathrm{E}} \\
\mathbf{J} / \mathbf{m o l}\end{array}$ \\
\hline \multicolumn{5}{|c|}{ System I: Triethanolamine +2-Methoxyethanol } \\
\hline $\mathbf{0}$ & 0.000 & 0.000 & 0.000 & 0.000 \\
\hline 0.2 & 68.35 & 4.56 & 11.50 & 84.407 \\
\hline 0.4 & 60.40 & 14.97 & 3.73 & 79.100 \\
\hline 0.6 & 50.64 & 33.61 & -13.01 & 71.232 \\
\hline 0.8 & 29.34 & 35.08 & -24.44 & 39.983 \\
\hline 1.0 & 0.000 & 0.000 & 0.000 & 0.000 \\
\hline \multicolumn{5}{|c|}{ System II: Triethanolamine +2-Ethoxyethanol } \\
\hline $\mathbf{0}$ & 0.000 & 0.000 & 0.000 & 0.000 \\
\hline 0.2 & 39.79 & -26.31 & 20.44 & 33.92 \\
\hline 0.4 & 68.70 & -5.60 & 3.83 & 66.94 \\
\hline 0.6 & 12.40 & -0.36 & -39.60 & -26.84 \\
\hline 0.8 & 20.67 & 21.09 & -30.39 & 11.37 \\
\hline 1.0 & 0.000 & 0.000 & 0.000 & 0.000 \\
\hline \multicolumn{5}{|c|}{ System II: Triethanolamine +2 -Butoxyethanol } \\
\hline 0 & 0.000 & 0.000 & 0.000 & 0.000 \\
\hline 0.2 & 20.12 & -41.27 & 15.91 & -5.25 \\
\hline 0.4 & 117.55 & 17.26 & -0.48 & 134.34 \\
\hline 0.6 & 138.17 & 67.35 & -19.35 & 186.17 \\
\hline 0.8 & 157.52 & 102.61 & -20.01 & 240.12 \\
\hline 1.0 & 0.000 & 0.000 & 0.000 & 0.000 \\
\hline
\end{tabular}




\subsection{Effective Kirkwood correlation factor $\left(\mathrm{g}^{\mathrm{eff}}\right)$}

The structural information about the liquids from the dielectric relaxation parameter may be obtained by using the effective Kirkwood correlation factor, $g^{\text {eff }}$ [28-29]. This factor is useful for obtaining information regarding orientation of electric dipoles in polar liquids. The ' $\mathrm{g}$ ' factor for the pure liquid may be obtained from the expression,

$$
\frac{4 \Pi N_{A} \mu^{2} \rho}{9 K T M} g=\frac{\left(\varepsilon_{0}-\varepsilon_{\infty}\right)\left(2 \varepsilon_{0}+\varepsilon_{\infty}\right)}{\varepsilon\left(\varepsilon_{\infty}+2\right)^{2}}
$$

$\mathrm{N}_{\mathrm{A}}$ is the Avogadro number, $\mu$ is the dipole moment in the gas phase, $\rho$ is the density, $\mathrm{K}$ is the Boltzmann's constant, $\mathrm{T}$ is the temperature in Kelvin, $\mathrm{M}$ is the molecular weight, $\left(\varepsilon_{0}\right)$ is the static dielectric constant and $\left(\varepsilon_{\infty}\right)$ is the dielectric constant at an optical frequency, which is the square of the refractive index.

Modified forms of this equation have been used to study the orientation of electric dipoles in binary mixture of Triethanolamine with 2-Alkoxyethanols. Equation (2) is modified by assuming that for the mixture $\mathrm{g}^{\text {eff }}$ has become effective Kirkwood correlation factor in the mixture. The Kirkwood correlation factor equation for the mixture may be expressed as [30].

$$
\frac{4 \Pi N_{A}}{9 K T}\left(\frac{\mu_{1}^{2} \rho_{1}}{M_{1}} \phi_{1}+\frac{\mu_{2}^{2} \rho_{2}}{M_{2}} \phi_{2}\right) g^{e f f}=\frac{\left(\varepsilon_{0 m}-\varepsilon_{\infty m}\right)\left(2 \varepsilon_{0 m}+\varepsilon_{\infty m}\right)}{\varepsilon_{0 m}\left(\varepsilon_{\infty m}+2\right)^{2}} .
$$

Where, $\mathrm{g}^{\text {eff }}$ is the effective Kirkwood correlation factor for a binary mixture, with $\phi_{1}$ and $\phi_{2}$ as volume fractions of liquids 1 and 2 respectively. The effective kirkwood correlation factor $\left(\mathrm{g}^{\text {eff }}\right)$ is clacuated by using equation (3).

The effective kirkwood correlation factor $\left(\mathrm{g}^{\text {eff }}\right)$ values are given in Table (4). In general, if the ( $\mathrm{g}^{\text {eff }}$ ) values are greater than unity which indicates the parallel orientation of dipoles and if it is less than unity which indicates the antiparallel orientation of dipoles. In our study, the $\left(\mathrm{g}^{\text {eff }}\right)$ values are increases with the increasing volume fraction of TEA. The $\left(\mathrm{g}^{\text {eff }}\right)$ values are greater than unity in all the systems studied, which means that the parallel orientation of dipoles are takes place. The electronegative Nitrogen atom $(\mathrm{N})$ present in the TEA and $\mathrm{OH}$ group of 2-Alkoxyethanols may having a possibility to form a hydrogen bond [26].

\subsection{Corrective kirkwood correlation factor $\left(\mathrm{g}_{\mathrm{f}}\right)$}

The corrective kirwood correlation factor $\left(\mathrm{g}_{\mathrm{f}}\right)$ is also a dielectric parameter which supplies essential information regarding interaction of the molecules of the mixture. For an ideal non-interacting mixture $\left(\mathrm{g}_{\mathrm{f}}\right)$ must be unity and the magnitude of the deviation of $\left(\mathrm{g}_{\mathrm{f}}\right)$ from unity indicates the magnitude of interaction between the liquds. (i.e) Greater the deviation from unity means larger the strength of interactions [31-32].

$$
\frac{4 \Pi N_{A}}{9 K T}\left(\frac{\mu_{1}^{2} \rho_{1} g_{1}}{M_{1}} \phi_{1}+\frac{\mu_{2}^{2} \rho_{2} g_{2}}{M_{2}} \phi_{2}\right) g_{f}=\frac{\left(\varepsilon_{0 m}-\varepsilon_{\infty m}\right)\left(2 \varepsilon_{0 m}+\varepsilon_{\infty m}\right)}{\varepsilon_{0 m}\left(\varepsilon_{\infty m}+2\right)^{2}}
$$

Where $\mathrm{N}_{\mathrm{A}}$ is Avogadronumber, $\mu$ is the dipole moment in the gas phase, $\rho$ is the density, $\mathrm{K}$ is the Boltzmann's constant, $\mathrm{T}$ is the Temperature in Kelvin, $\mathrm{M}$ is the molecular weight, $\left(\varepsilon_{\mathrm{om}}\right)$ is the static dielectric constant of mixture and $\left(\varepsilon_{\infty}\right)$ is the dielectric constant at an optical frequency which is the square of the refractive index of the mixture.

The corrective Kirkwood correlation factor $\left(\mathrm{g}_{\mathrm{f}}\right)$ was calculated by using equation (4). In the system of TEA with 2Alkoxyethanols, the values of $\left(g_{f}\right)$ are close to unity for all the system taken for the study. The $\left(g_{f}\right)$ values are found to be slightly less than unity from TEA+2-ME, TEA+2-EE $(0.2,0.4)$ and TEA+2-BE $(0.4,0.6,0.8)$ system indicating that effective dipoles in the mixture are smaller than the average of those in the pure liquids. Further, the $\left(\mathrm{g}_{\mathrm{f}}\right)$ values are found to be slightly greater than unity for TEA+2-EE $(0.6,0.8)$ and TEA+ 2-BE $(0.2)$ systems for all the concentrations, indicating that the effective dipoles in the mixture are greater than the average of those in the pure liquids. The values of $\left(\mathrm{g}_{\mathrm{f}}\right)$ are found to depend more on concentrations than the temprature, as reported [33-34]. 


\subsection{Bruggeman factor $\left(\mathbf{f}_{\mathrm{B}}\right)$}

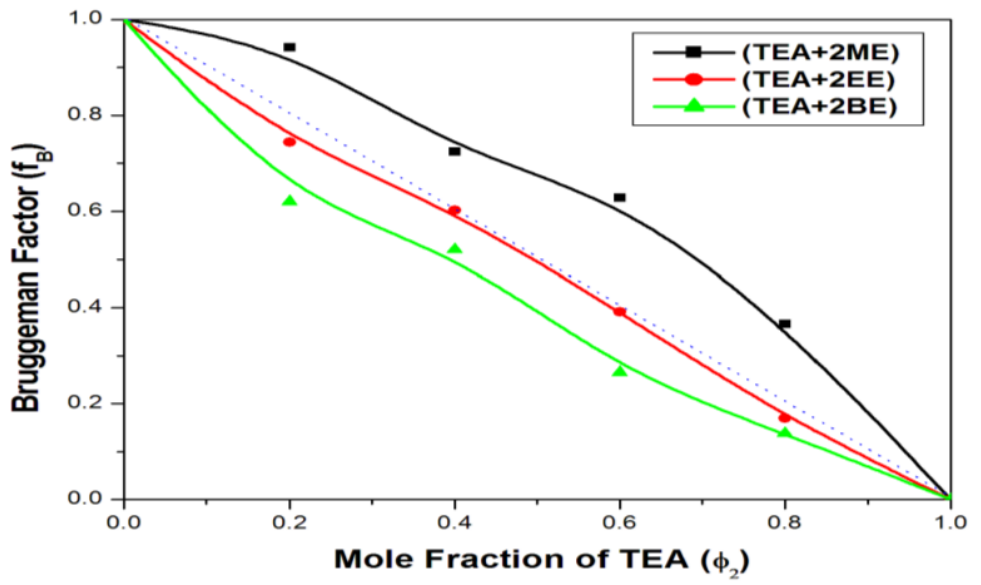

Fig :4. Bruggeman factor $V s$ volume fraction of Triethanolamine $\left(\phi_{2}\right)$

The information about the solute - solvent interaction is given by the Bruggeman factor. The effective volume of the solute gets modified by solute - solvent interactions and is best illustrated by the non - linearity of the Bruggeman formula [35],

$$
f_{B}=\left(\frac{\left(\varepsilon_{0 m}-\varepsilon_{02}\right)}{\left(\varepsilon_{01}-\varepsilon_{02}\right)}\right)\left(\frac{\varepsilon_{01}}{\varepsilon_{o m}}\right)^{1 / 3}=\left(1-\phi_{2}\right)
$$

According to equation (2), a graph is drawn between $\mathrm{f}_{\mathrm{B}}$ and volume fraction of amine. The estimated values of $\mathrm{f}_{\mathrm{B}}$ are shown in Fig (4). It can be seen from the figure that $\left(\mathrm{f}_{\mathrm{B}}\right)$ is not a linear function of volume fraction of TEA. Which indicate that the inter-molecular interaction is taking place in the mixture. The upward deviation from the Bruggeman line is observed for TEA+2-ME system. Whereas the downward deviation from the Bruggeman line is observed for TEA+2-BE systems. There is slight deviation from the Bruggeman line is observed for TEA+ 2-EE systems. Which means that the interaction is more in TEA+2-ME system, minimum in TEA+2-BE system and moderate in TEA+2-EE system. The non-linearity of the curves indicate hetero-interaction which may be due to hydrogen bonding of the - $\mathrm{OH}$ group of alcohols with $\mathrm{N}$ atom of TEA [36].

\subsection{Excess dielectric constant $\left(\varepsilon^{\mathrm{E}}\right)$}

The excess dielectric constant is defined as [37]

$$
\varepsilon^{\mathrm{E}}=\left(\varepsilon_{0}-\varepsilon_{\infty}\right)_{m}-\left\{\left(\varepsilon_{0}-\varepsilon_{\infty}\right)_{1} \phi_{1}+\left(\varepsilon_{0}-\varepsilon_{\infty}\right)_{2} \phi_{2}\right\}
$$

Where $\phi_{1}$ and $\phi_{2}$ represents the volume fraction of liquid 1 (2-Alkoxyethanols) and liquid 2 (Triethanolamine). The excess dielectric constant $\left(\varepsilon^{\mathrm{E}}\right)$ provides information about the formation of multimers in the mixture as follows:

1. $\left(\varepsilon^{\mathrm{E}}\right)=0$ indicates that there is no interaction between the components in the mixture.

2. $\left(\varepsilon^{\mathrm{E}}\right)<0$ reveals that components in the mixture may form closed multimers leading to the less effective dipoles due to the interaction between the components in such a way that the effective dipole moment gets reduced.

3. $\left(\varepsilon^{\mathrm{E}}\right)>0$ denotes that components in the mixture interact in such a way that the effective dipole moment is increased.

In an ideal mixture of polar liquids if the molecules are interacting, a non linear variation in dielectric constant and relaxation time occurs. This confirms that the intermolecular association is taking place in these systems.

In the present study, the negative values of excess dielectric constant $\left(\varepsilon^{\mathrm{E}}\right)$ were observed for TEA+2-ME and TEA+2BE Systems. The negative value of $\left(\varepsilon^{\mathrm{E}}\right)$ indicates that molecules of the mixtures may form multimers structures via hydrogen bonding in such a way that the effective dipoles get reduced. In the case of TEA+2-EE system, positive value of excess dielectric constant $\left(\varepsilon^{\mathrm{E}}\right)$ is obtained. The positive value of excess dielectric constant $\left(\varepsilon^{\mathrm{E}}\right)$ indicates that molecules of the mixtures may form monomers or dimer structures in such a way that the number of effective dipoles increases. The components in the 
mixture interact in such a way that the effective dipole moment is increased. The excess property related to static dielectric constant provides significant information regarding interaction between the polar-polar liquid mixtures [38].

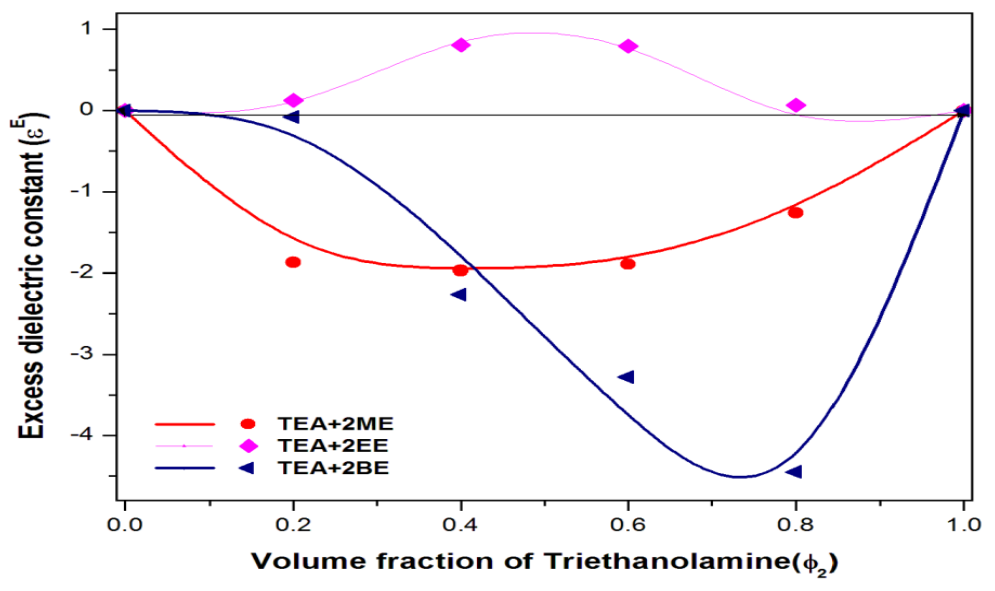

Fig : 5. Excess dielectric constant $\left(\varepsilon^{\mathbf{E}}\right) V s$ volume fraction of Triethanolamine $\left(\phi_{2}\right)$

\subsection{Excess inverse relaxation time $(1 / \tau)^{\mathrm{E}}$}

The excess inverse relaxation time is defined as [39],

$$
\left(\frac{1}{\tau}\right)^{E}=\left(\frac{1}{\tau}\right)_{m}-\left\{\left(\frac{1}{\tau}\right)_{1} \emptyset_{1}+\left(\frac{1}{\tau}\right)_{2} \emptyset_{2}\right\}
$$

Where $\left(\frac{1}{\tau}\right)^{E}$ is excess inverse relaxation time, which represents the average broadening of dielectric spectra. The inverse relaxation time analogy is taken from spectral line broadening in the resonant spectroscopy [40]. The information regarding the dynamics of liquids 1 and 2 from this excess property is a follows:

1. $\left(\frac{1}{\tau}\right)^{E}=0:$ there is no change in the dynamics of liquids 1 and 2 interaction.

2. $\left(\frac{1}{\tau}\right)^{E}<0$ : the liquids 1 and 2 interactions produces a field such that the effective dipoles rotates slowly.

3. $\left(\frac{1}{\tau}\right)^{E}>0$ : the liquids 1 and 2 interaction produces a field such that the effective dipoles rotate fastly (i.e.) the fields will co-operate in the rotation of dipoles.

In our study, the excess inverse relaxation time $(1 / \tau)^{\mathrm{E}}$ values are negative for all the systems such as TEA with 2-ME, 2-EE and 2-BE binary mixtures. This indicates that the addition of TEA with 2-Alkoxyethanols has created a hindering field such that the effective dipoles rotate slowly [41].

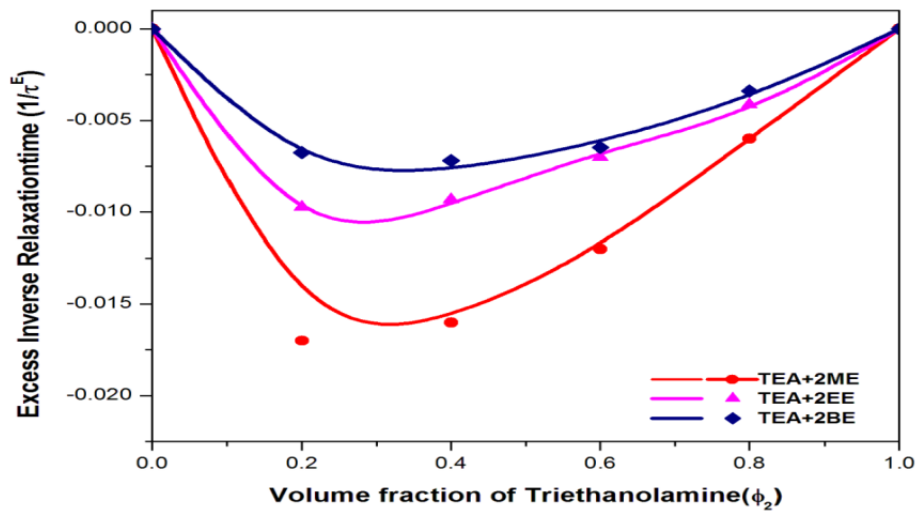

Fig : 6. Excess inverse relaxation time $\left(1 / \tau^{\mathrm{E}}\right) V s$ volume fraction of Triethanolamine $\left(\phi_{2}\right)$ 
The excess parameters were expressed mathematically by Redlich-Kister type polynomial equation [42]. The R-K equation is given as follows:

$$
y^{E}=x_{1}\left(1-x_{1}\right) \sum_{k}^{n} a_{i}\left(1-2 x_{1}\right) i
$$

Where $\mathrm{y}^{\mathrm{E}}$ indicates the excess values and $\mathrm{a}_{\mathrm{i}}$ are the co-efficient. The standard deviation has been determined by the following formula

$$
\sigma=\left[\frac{\sum\left(X_{\mathrm{exp}}-X_{c a l}\right)^{2}}{n-p}\right]^{1 / 2}
$$

Where $\mathrm{n}$ is number of experimental points and $\mathrm{p}$ is number of coefficients. The excess Dielectric constant and excess inverse relaxation time were fitted with Redlich-Kister type polynomial equation using nonlinear regression to estimate the coefficients and standard deviation. In Figs. (5) and (6) the smooth solid lines represents the mathematical calculation of excess dielectric constant and excess inverse relaxation time $(1 / \tau)^{\mathrm{E}}$ values. The coefficients and standard deviation are calculated and are given in Table (5).

\subsection{Excess Helmholtz free energy $\left(\Delta \mathbf{F}^{\mathrm{E}}\right)$}

The study of Excess Helmholtz free energy can give information on the interaction between the molecules of participating liquids in the mixture through the breaking mechanism of the H-bonds. The excess free energy due to mixing is given as [43].

$$
\left(\Delta \mathrm{F}^{\mathrm{E}}\right)=\left(\Delta \mathrm{F}_{0 \mathrm{r}}^{\mathrm{E}}\right)+\left(\Delta \mathrm{F}_{\mathrm{rr}}^{\mathrm{E}}\right)+\Delta \mathrm{F}_{12}^{\mathrm{E}}
$$

Where, $\left(\Delta \mathrm{F}_{0 \mathrm{r}}^{\mathrm{E}}\right)$ represents the excess dipolar energy due to long range electrostatic interaction between similar molecules. $\left(\Delta \mathrm{F}_{\text {rr }} \mathrm{E}\right)$ represents the excess dipolar energy due to short range interaction between similar molecules and $\left(\Delta \mathrm{F}_{12} \mathrm{E}^{\mathrm{E}}\right)$ represents the excess free energy due to short range interaction between dissimilar molecules. The above terms are given in detail in equation $(11,12 \& 13)$.

$$
\begin{gathered}
\Delta F^{E}=-\frac{N_{A}}{2}\left\{\begin{array}{l}
{\left[\sum_{r=1,2} X_{r}^{2} \mu_{r}^{2}\left(R_{f r}-R_{f r}^{0}\right)\right]} \\
+\left[\sum_{r=1,2} X_{r}^{2} \mu_{r}^{2}\left(g_{r r}-1\right) \times\left(R_{f r}-R_{f r}^{0}\right)\right] \\
+\left[X_{1} X_{2} \mu_{1} \mu_{2}\left(g_{12}-1\right) \times\left(R_{f 1}+R_{f 2}-R_{f 1}^{0}-R_{f 2}^{0}\right)\right]
\end{array}\right\} \\
R_{f r}^{0}=\left(\frac{\left.8 \pi N_{A}\right) \frac{\left(\varepsilon_{r}-1\right)\left(\varepsilon_{\infty}+2\right)}{\left(2 \varepsilon_{r}+\varepsilon_{\infty}\right)}}{\ldots \ldots \ldots . . .}\right. \\
R_{f r}=\left(\frac{\left.8 \pi N_{A}\right) \frac{\left(\varepsilon_{m}-1\right)\left(\varepsilon_{\infty r}+2\right)}{\left.9 V_{r}\right)}}{\left(2 \varepsilon_{m}+\varepsilon_{\infty r}\right)}\right.
\end{gathered}
$$

$\mathrm{Vr}$ is the molar volume of the components. $\varepsilon_{\mathrm{r}}$ and $\varepsilon_{\infty \mathrm{r}}$ are the static dielectric constant and static dielectric constant at optical frequencies of the pure liquids respectively.

The long range and short range interaction between the dipoles can be studied from the thermodynamic parameter, (i.e) excess Helmholtz free energy $\left(\Delta \mathrm{F}^{\mathrm{E}}\right)$. The different components of $\Delta \mathrm{F}^{\mathrm{E}}$ such as $\Delta \mathrm{F}_{0 \mathrm{r}}^{\mathrm{E}}, \Delta \mathrm{F}_{\mathrm{rr}}^{\mathrm{E}}$ and $\Delta \mathrm{F}_{12}^{\mathrm{E}}$ are given in Table (6).

In the present study, $\Delta \mathrm{F}_{0 \mathrm{r}}^{\mathrm{E}}$, values are positive for all the three systems studied (i.e) TEA with 2-ME, 2-EE and 2-BE. These values are decreases as the volume fraction of TEA increases in the case of TEA with 2-ME and increases in the case of 
TEA with 2-BE. Whereas it is random positive in the case of TEA with 2-EE. The positive values of $\Delta \mathrm{F}_{0 \mathrm{r}}^{\mathrm{E}}$ indicate the existence of attractive forces.

The second term $\left(\Delta \mathrm{F}_{\mathrm{rr}}^{\mathrm{E}}\right)$ gives the excess free energy due to short range interaction between the like molecules. The positive values of $\left(\Delta \mathrm{F}_{\mathrm{rr}}{ }^{\mathrm{E}}\right)$ is obtained for TEA+2-ME system and both positive and negative values for TEA+2-EE and TEA+2$\mathrm{BE}$ systems. Positive values of $\left(\Delta \mathrm{F}_{\mathrm{rr}}^{\mathrm{E}}\right)$ indicates that the strong short range interaction through $\mathrm{H}$-bonding. $\left.\left(\Delta \mathrm{F}_{12}\right)^{\mathrm{E}}\right)$ represents excess free energy due to short range interaction between dissimilar molecules. All the three systems has both positive and negative values of $\left(\Delta \mathrm{F}_{12}{ }^{\mathrm{E}}\right)$ which indicates that the hetero interaction between the molecules of the participating liquids.

The excess Helmholtz free energy values are completely positive for TEA+2-ME system and both positive and negative for TEA+2-EE and TEA+2-BE systems. The positive values indicates that the formation of $\beta$-clusters with antiparallel alignment of dipoles [44]. The positive and negative values indicate that the formation of $\alpha$-cluster to $\beta$-clusters with parallel to anti-parallel alignment of dipoles takes place. The $\Delta \mathrm{F}^{\mathrm{E}}$ values are mainly contributed by long range electrostatic interaction $\Delta \mathrm{F}_{0 \mathrm{r}}^{\mathrm{E}}$ and not due to the short range electrostatic interaction $\Delta \mathrm{F}_{\mathrm{rr}}^{\mathrm{E}}$ [45].

\subsection{FT-IR Study}

FT-IR spectroscopy has been carried out to study the molecular interaction for the binary solutions of Triethanolamine (TEA) with 2-Alkoxyethaols (2-ME, 2-EE and 2-BE). The FT-IR spectrum of pure liquids such as Triethanolamine, 2Methoxyethanol, 2-Ethoxyethanol

and

2-Butoxyethanol and their binary liquid mixtures of nearby middle concentrations (i.e) (0.4) and (0.6) were recorded and were shown in fig (7), (8) and (9) and (10) [46].

In our study, The $\mathrm{O}-\mathrm{H}$ stretching vibrations are observed for pure TEA in the range for at $3295 \mathrm{~cm}^{-1}, 2-$ Methoxyethanol range at $3392 \mathrm{~cm}^{-1}$, 2-Ethoxyethanol for at 3365 cm $\mathrm{cm}^{-1}$ and for 2-Butoxyethanol at $3385 \mathrm{~cm}^{-1}$. FT-IR spectrum is taken at room temperature and two nearby equimolar concentration of the resultant absorption bands of $\mathrm{O}-\mathrm{H}$ stretching vibration for TEA $40 \%+2-\mathrm{ME} 60 \%$ at $3361 \mathrm{~cm}^{-1}$ and TEA $60 \%+2-\mathrm{ME} 40 \%$ are at $3337 \mathrm{~cm}^{-1}$. The resultant absorption bands of O-H stretching vibration for TEA $40 \%+2-E E 60 \%$ are at $3354 \mathrm{~cm}^{-1}$ and TEA $60 \%+2-\mathrm{EE} \quad 40 \%$ are at $3337 \mathrm{~cm}^{-1}$. Similarly the O-H stretching vibrations for TEA 40\%+ 2-BE $60 \%$ are at $\left(3357 \mathrm{~cm}^{-1}\right)$ and TEA $60 \%+2-\mathrm{BE} 40 \%$ are at $\left(3334 \mathrm{~cm}^{-1}\right)$. These wave number shifts indicates the formation of weak inter-molecular interactions between the participating of the molecules of the liquids.

. The $\mathrm{CH}_{2}$ asymmetric stretching vibrations are observed at $2929 \mathrm{~cm}^{-1}$ and $2932 \mathrm{~cm}^{-1}$ for two near equimolar concentration for TEA+2-ME system. The same was observed at $2934 \mathrm{~cm}^{-1}$ and $2938 \mathrm{~cm}^{-1}$ for two near equimolar concentration of TEA+2EE system. Similarly at $2933 \mathrm{~cm}^{-1}$ and $2936 \mathrm{~cm}^{-1}$ for TEA+2-BE system.

FTIR Spectrum of TEA with 2-ME, 2-EE and 2-BE are shown in figs (8), (9), (10) respectively. For two near equimolar concentration like (0.4), (0.6). In addition, the $\mathrm{C}-\mathrm{C}-\mathrm{O}$ stretching vibrations and $\mathrm{O}-\mathrm{CH}_{2}-\mathrm{C}$ asymmetric stretching vibrations values are slightly different at various concentrations $(0.4 \& 0.6)$ of binary mixture solutions. This may be due to the frequency shifts and caused by the inter-molecular interaction like hydrogen bonding taking place between the molecules of the participating liquids.

Table: 7. FT-IR Spectral band assignments for Triethanolamine+2-Alkoxyethanols with nearby equimolar concentration

\begin{tabular}{|c|c|c|c|}
\hline \multirow[t]{2}{*}{ Compounds } & \multirow[t]{2}{*}{ Vibration modes } & \multicolumn{2}{|c|}{ Wave number $\left(\mathrm{cm}^{-1}\right)$} \\
\hline & & Corresponding peak values & Shifted peak values \\
\hline Triethanolamine & $\mathrm{O}-\mathrm{H}$ & 3295 & \\
\hline 2-Methoxyethanol & $\mathrm{O}-\mathrm{H}$ & 3392 & \\
\hline $\begin{array}{l}\text { Triethanolamine }(40 \%)+ \\
\text { 2-Methoxyethanol }(60 \%)\end{array}$ & $\mathrm{O}-\mathrm{H}$ & 3361 & 31 \\
\hline & $\mathrm{CH}_{2}$ asymmetric stretch & 2929 & \\
\hline & C-C-O stretch & 1235 & \\
\hline & $\mathrm{O}-\mathrm{CH}_{2}-\mathrm{C}$ asymmetric stretch & 1061 & \\
\hline $\begin{array}{l}\text { Triethanolamine }(60 \%)+ \\
2-\text { Methoxyethanol }(40 \%)\end{array}$ & $\mathrm{O}-\mathrm{H}$ & 3337 & 55 \\
\hline & $\mathrm{CH}_{2}$ asymmetric stretch & 2932 & \\
\hline & C-C-O stretch & 1239 & \\
\hline & $\mathrm{O}-\mathrm{CH}_{2}-\mathrm{C}$ asymmetric stretch & 1061 & \\
\hline
\end{tabular}




\begin{tabular}{|l|c|c|c|}
\hline \multicolumn{1}{|c|}{ Compounds } & Vibration modes & \multicolumn{2}{c|}{ Wave number $\left(\mathbf{c m}^{-1}\right)$} \\
\hline 2-Ethoxyethanol & $\mathrm{O}-\mathrm{H}$ & 3365 & \\
\hline Triethanolamine & $\mathrm{O}-\mathrm{H}$ & 3295 & 11 \\
\hline $\begin{array}{l}\text { Triethanolamine }(40 \%)+ \\
\text { 2-Ethoxyethanol }(60 \%)\end{array}$ & $\mathrm{O}-\mathrm{H}$ & 2934 & \\
\hline & $\mathrm{CH}_{2}$ asymmetric stretch & 1228 & \\
\hline & $\mathrm{C}-\mathrm{C}-\mathrm{O}$ stretch & 1035 & 28 \\
\hline $\begin{array}{l}\text { Triethanolamine }(60 \%)+ \\
\text { 2-Ethoxyethanol }(40 \%)\end{array}$ & $\mathrm{O}-\mathrm{CH}_{2}-\mathrm{C}$ asymmetric stretch & 3337 & \\
\hline & $\mathrm{O}-\mathrm{H}$ & 2938 & \\
\hline & $\mathrm{CH}_{2}$ asymmetric stretch & 1237 & \\
\hline & $\mathrm{C}-\mathrm{C}-\mathrm{O}$ stretch & 1063 & \\
\hline 2-Butoxyethanol & $\mathrm{O}-\mathrm{CH}_{2}-\mathrm{C}$ asymmetric stretch & 3385 & \\
\hline Triethanolamine & O-H & 3295 & \\
\hline $\begin{array}{l}\text { Triethanolamine }(40 \%)+ \\
\text { 2-Butoxyethanol }(60 \%)\end{array}$ & O-H & 3357 & \\
\hline & $\mathrm{CH}_{2}$ asymmetric stretch & 2933 & \\
\hline & $\mathrm{C}-\mathrm{C}-\mathrm{O}$ stretch & 1237 & \\
\hline & $\mathrm{O}-\mathrm{CH}_{2}-\mathrm{C}$ asymmetric stretch & 1037 & \\
\hline $\begin{array}{l}\text { Triethanolamine }(60 \%)+ \\
\text { 2-Butoxyethanol }(40 \%)\end{array}$ & O-H & 3334 & \\
\hline & $\mathrm{CH}_{2}$ asymmetric stretch & 2936 & \\
\hline & $\mathrm{C}-\mathrm{C}-\mathrm{O}$ stretch & 1244 & \\
\hline & $\mathrm{O}-\mathrm{CH}_{2}-\mathrm{C}$ asymmetric stretch & 1066 & \\
\hline
\end{tabular}

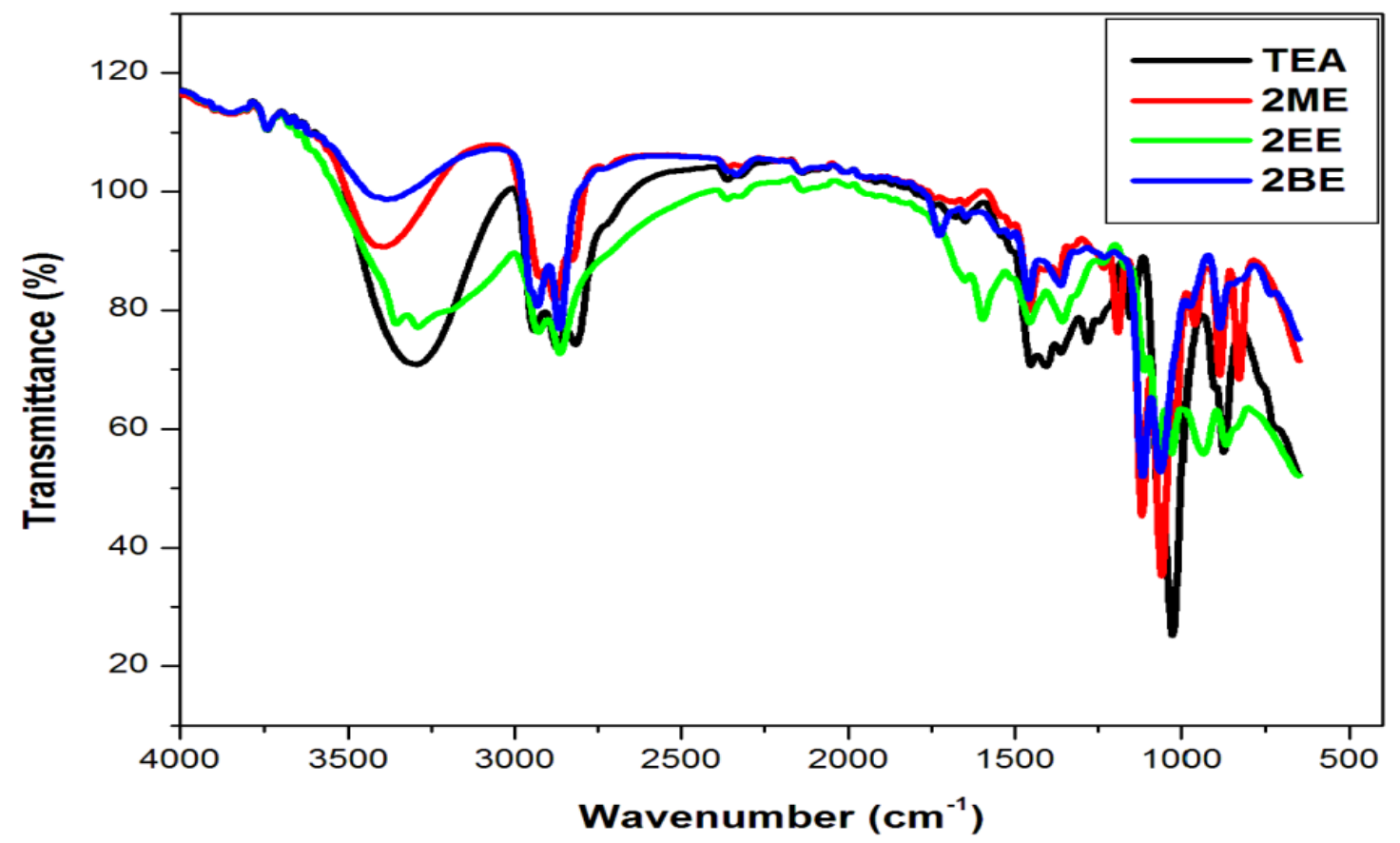

Fig: 7. The FT-IR spectrum of TEA and 2-Alkoxyethanols pure liquids 


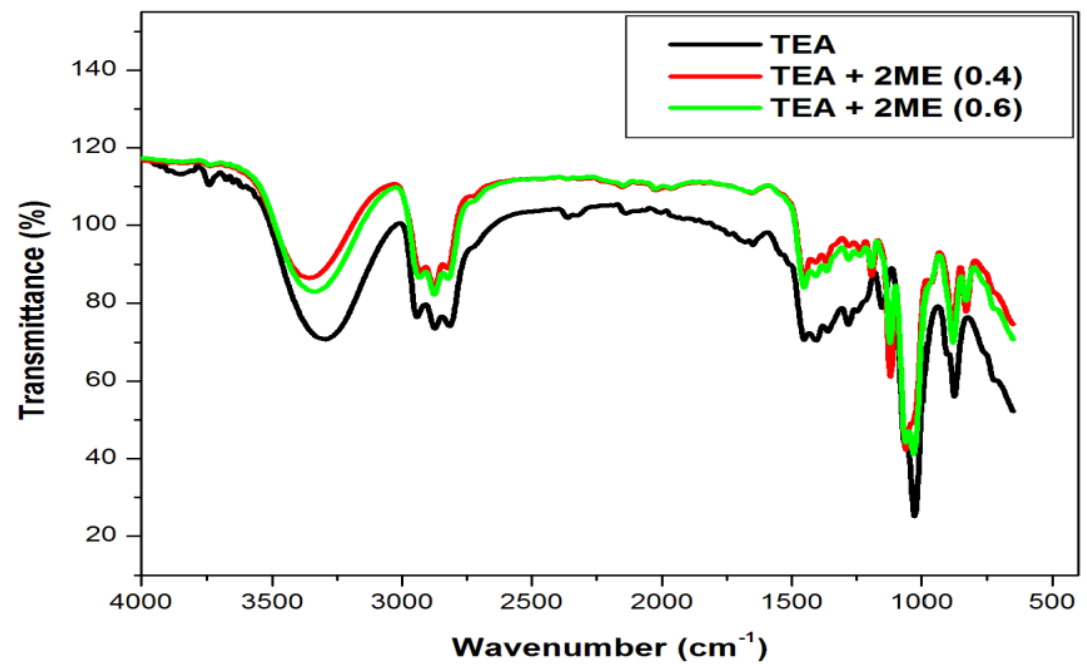

Fig: 8.The FT-IR spectrum of TEA with $2-M E$ at nearby middle concentrations $(0.4 \& 0.6)$

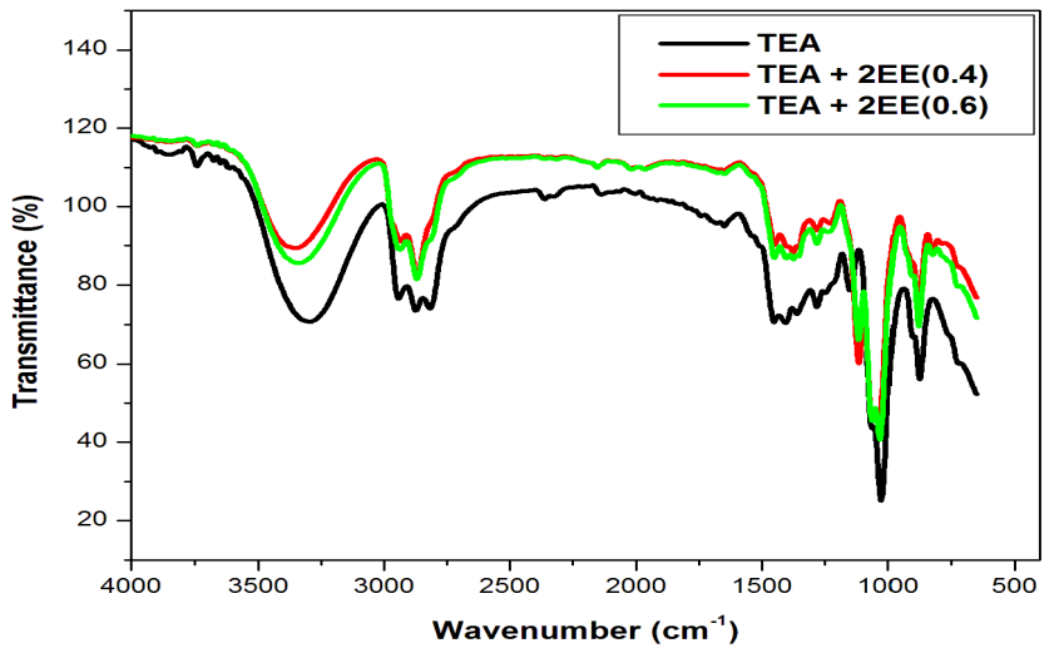

Fig: 9. The FT-IR spectrum of TEA with 2 -EE at nearby middle concentrations $(0.4 \& 0.6)$

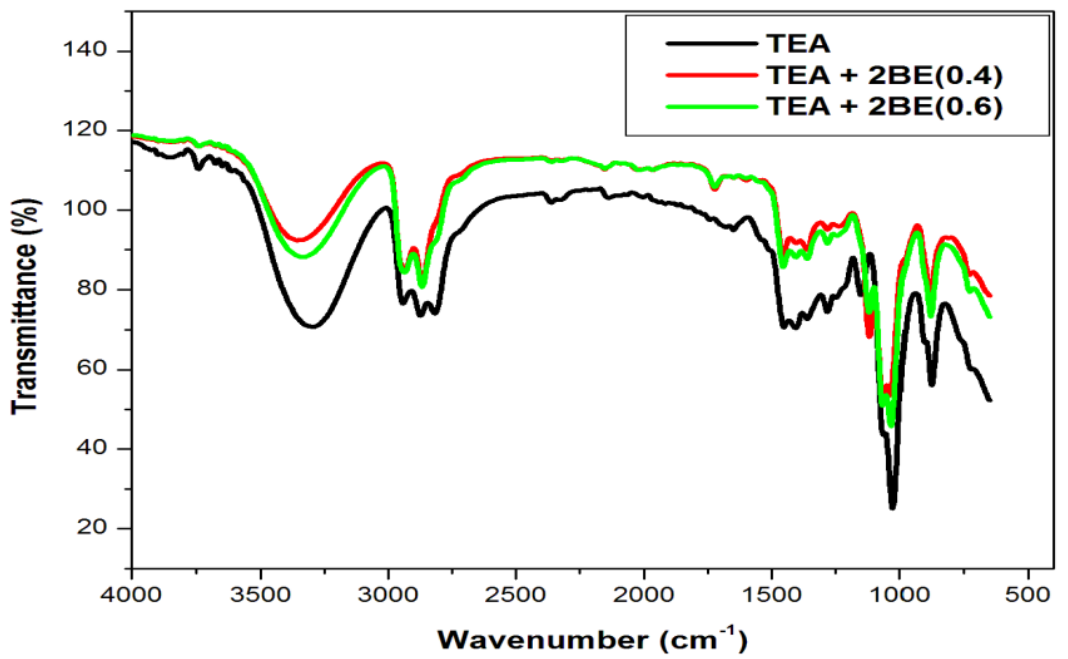

Fig: 10.The FT-IR spectrum of TEA with 2 -BE at nearby middle concentrations $(0.4 \& 0.6)$ 


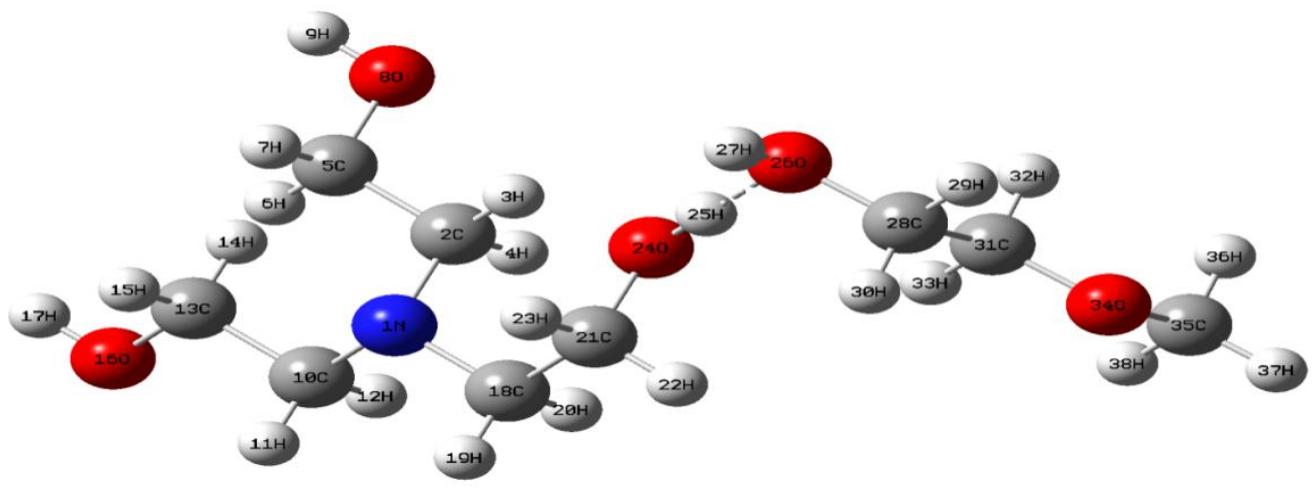

Fig: 11. Hydrogen bond interaction between Triethanolamine $\left(\mathrm{C}_{6} \mathrm{H}_{15} \mathrm{NO}_{3}\right)+$ 2-Methoxyethanol $\left(\mathrm{C}_{3} \mathrm{H}_{8} \mathrm{O}_{2}\right)$

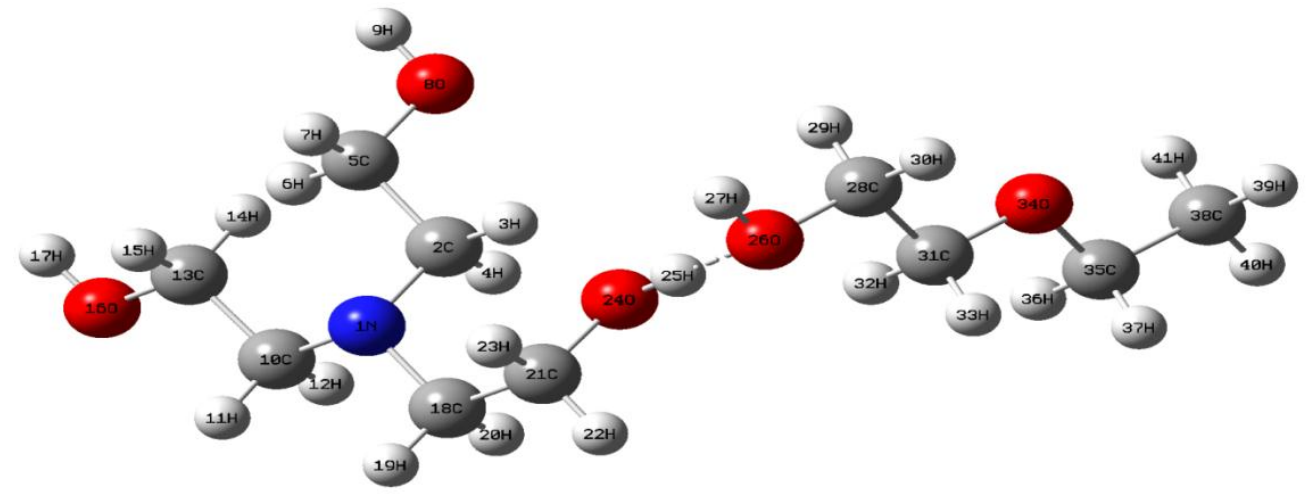

Fig: 12. Hydrogen bond interaction between Triethanolamine $\left(\mathrm{C}_{6} \mathrm{H}_{15} \mathrm{NO}_{3}\right)+$ 2-Ethoxyethanol $\left(\mathrm{C}_{4} \mathrm{H}_{10} \mathrm{O}_{2}\right)$

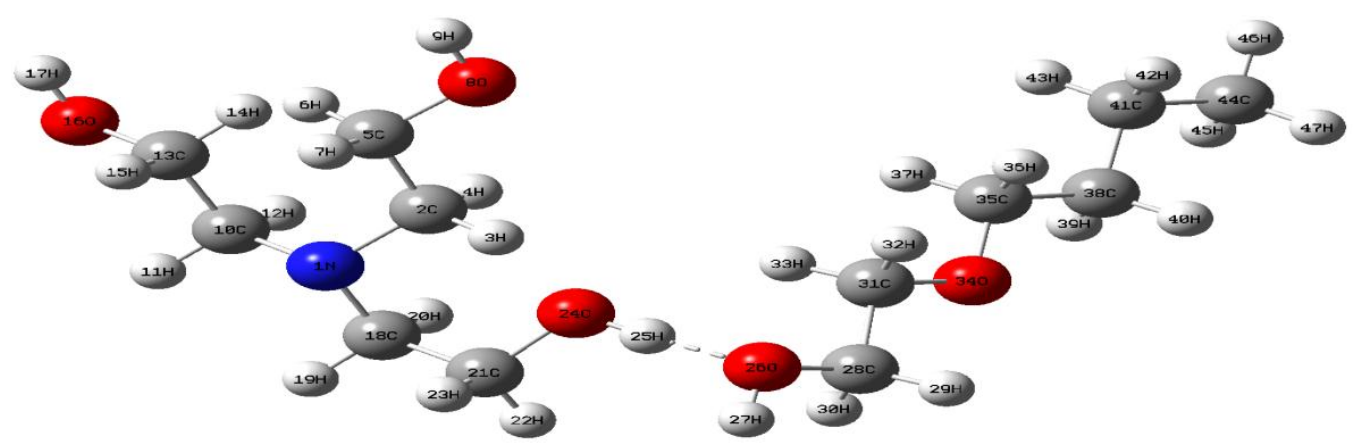

Fig: 13. Hydrogen bond interaction between Triethanolamine $\left(\mathrm{C}_{6} \mathrm{H}_{15} \mathrm{NO}_{3}\right)+$ 2-Butoxyethanol $\left(\mathrm{C}_{6} \mathrm{H}_{14} \mathrm{O}_{2}\right)$

\section{CONCLUSION}

- Time Domain Reflectometry technique is a powerful tool to identify the inter and intra-molecular interactions between the liquids Triethanolamine and 2-Methoxyethanol, 2-Ethoxyethanol, 2-Butoxyethanol. The Dielectric permittivity $\left(\varepsilon^{\prime}\right)$, Dielectric loss $\left(\varepsilon^{\prime \prime}\right)$, Relaxation time $(\tau)$ were determined from the complex permittivity spectra of pure liquids and binary mixtures. 
- Effective Kirkwood correlation factor $\left(\mathrm{g}^{\text {eff }}\right)$ values of all the systems are greater than one which idicates parallel orientation of dipoles takes place between the system studied. Hence this tendenecy leads to the interaction between $\mathrm{OH}$ group of alcohol and Nitrogen atom of TEA molecules.

- Corrective Kirkwood correlation factor $\left(g_{f}\right)$ values for all the systems are almost less than unity. which indicates that the less effective dipoles in the mixture are smaller than the average of those in the pure liquids.

- Bruggeman factor $\left(\mathrm{f}_{\mathrm{B}}\right)$ shows that there exist some interactions among the molecules of the participating liquids. Which are revealed by their magnitude of deviations from the ideal Bruggeman dotted lines. In our study, A nonlinear relation is obtained between Bruggeman factor $\left(\mathrm{f}_{\mathrm{B}}\right)$ and volume fraction of TEA+2-ME, TEA+2-EE and TEA+2-BE binary systems, which indicate that inter-molecular interaction are taking place in the mixture.

- The maximum upward deviation from the linearity is observed for TEA+2-ME system. The most downward deviation occurs in TEA+2-EE and TEA+2-BE systems. The non-linearity of the curves indicate hetero-interaction which may be due to hydrogen bonding of the $-\mathrm{OH}$ group of alcohol. which indicates that molecules of the mixture interact in such a way that the effective dipolemoment gets increased and there is a probability for the formation of linear multimers.

- Excess dielectric constant $\left(\varepsilon^{\mathrm{E}}\right)$ values for TEA+2-ME and TEA+2-BE systems were negative. The negative value of $\left(\varepsilon^{\mathrm{E}}\right)$ indicates that molecules of the mixtures may form multimers structures via hydrogen bonding in such a way that the effective dipoles get reduced. In the case of TEA+2-EE system, positive value of excess dielectric constant $\left(\varepsilon^{\mathrm{E}}\right)$ is obtained. The positive value of excess dielectric constant $\left(\varepsilon^{\mathrm{E}}\right)$ indicates that molecules of the mixtures may form monomers or dimer structures in such a way that the number of effective dipoles increases. Components in the mixture interact in such a way that the effective dipole moment is increased.

- Excess inverse relaxation time $(1 / \tau)^{\mathrm{E}}$ values obtained for all the systems are negative. Which means they created a hindering field such that the effective dipole rotates slowly, due to the formation of hydrogen bonded structures. The free energy of activation for relaxation time $\left(\Delta \mathrm{F}_{\tau}\right)$ for TEA+ 2-Alkoxyethanols systems indicates that the relaxation time involves rotational motion only and not due to translational motion.

- The excess Helmholtz free energy $\left(\Delta \mathrm{F}^{\mathrm{E}}\right)$ values are completely positive for TEA+ 2-ME system and both positive and negative for TEA+2-EE and TEA+2-BE systems. The positive values indicates that the formation of $\beta$-clusters with anti-parallel alignment of dipoles. The positive and negative values indicate that the formation $\alpha$-cluster to $\beta$-clusters with parallel to anti-parallel alignment of dipoles takes place. The $\Delta \mathrm{F}^{\mathrm{E}}$ values are mainly contributed by long range electrostatic interaction $\Delta \mathrm{F}_{0 \mathrm{r}}{ }^{\mathrm{E}}$ and not due to the short range electrostatic interaction $\Delta \mathrm{F}_{\mathrm{rr}}^{\mathrm{E}}$.

- FT-IR spectra analysis confirms the H-bond interaction takes place in between the participating liquid molecules. It is confirmed that the interaction takes place between the liquid mixtures are weak type of interactions like dispersive forces, vanderwalls forces dipole-dipole interaction or $\mathrm{H}$ - bonding.

\section{REFERENCES}

[1]. Pawar, V.P., 2006, Dielectric relaxation of propan-1-ol with chlorobenzene, 1, 2-dichloroethane, and dimethylene chloride at $(288,298,308$, and 318) $\mathrm{K}$ using time-domain reflectometry technique, Journal of Chemical \& Engineering Data, 51(3), pp.882-885.

[2]. Patil, S.P., Chaudhari, A.S., Lokhande, M.P., Lande, M.K., Shankarwar, A.G., Helambe, S.N., Arbad, B.R. and Mehrotra, S.C., 1999, Dielectric measurements of aniline and alcohol mixtures at 283, 293, 303, and $313 \mathrm{~K}$ using the time domain technique, Journal of Chemical \& Engineering Data, 44(5), pp.875-878.

[3]. Khirade, P.W., Chaudhari, A., Shinde, J.B., Helambe, S.N. and Mehrotra, S.C., 1999, Static dielectric constant and relaxation time measurements on binary mixtures of dimethyl sulfoxide with ethanol, 2-ethoxyethanol, and propan-1-ol at 293, 303, 313, and 323 K, Journal of Chemical \& Engineering Data, 44(5), pp.879-881.

[4]. Sengwa, R.J., Khatri, V. and Sankhla, S., 2008, Dielectric properties and hydrogen bonding interaction behaviour in binary mixtures of glycerol with amides and amines, Fluid Phase Equilibria, 266(1-2), pp.54-58,

[5]. Pawar, V.P. and Mehrotra, S.C., 2003. Dielectric relaxation study of dimethylene chloride with ethanol using time domain reflectometry, Journal of molecular liquids, 108(1-3), pp.95-105.

[6]. Prajapati, A.N., Vyas, A.D., Rana, V.A. and Bhatnagar, S.P., 2010, Dielectric relaxation and dispersion studies of mixtures of 1-propanol and benzonitrile in pure liquid state at radio and microwave frequencies, Journal of Molecular Liquids, 151(1), pp.12-16.

[7]. Pawar, V.P., Patil, A.V., Patil, A.R. and Mehrotra, S.C., 2010, Dielectric relaxation study of solute-solvent interaction between dimethylene chloride and dimethylformamide using time domain reflectometry, Journal of Molecular Liquids, 155(1), pp.16-19.

[8]. Achole, B.D., Patil, A.V., Pawar, V.P. and Mehrotra, S.C., 2011, Study of interaction through dielectrics: Behavior of- OH group molecules from $10 \mathrm{MHz}$ to $20 \mathrm{GHz}$, Journal of Molecular Liquids, 159(2), pp.152-156. 
[9]. Sengwa, R.J., Sankhla, S. and Khatri, V., 2009, Dielectric constant and molecular association in binary mixtures of N, Ndimethylethanolamine with alcohols and amides, Fluid Phase Equilibria, 285(1-2), pp.50-53.

[10]. Patil, A.V., Shinde, G.N. and Pawar, V.P., 2012, Dielectric relaxation study of hydrogen bonded structures in ethanolamine with diethanolamine using TDR technique, Journal of Molecular Liquids, 168, pp.42-46.

[11]. Sengwa, R.J., Sankhla, S. and Khatri, V., 2009, Dielectric constant and molecular association in binary mixtures of N, Ndimethylethanolamine with alcohols and amides, Fluid Phase Equilibria, 285(1-2), pp.50-53.

[12]. Jie, Q. and Guo-Zhu, J., 2013, Dielectric Constant of Polyhydric Alcohol-DMSO Mixture Solution at the Microwave Frequency. The Journal of Physical Chemistry A, 117(48), pp.12983-12989.

[13]. Joshi, Y.S. and Kumbharkhane, A.C., 2012, Study of dielectric relaxation and hydrogen bonding in water+ 2-butoxyethanol mixtures using TDR technique. Fluid Phase Equilibria, 317, pp.96-101.

[14]. Mohan, A., M. Malathi., 2018, Dielectric relaxation and thermodynamic studies on binary mixturesolutions of 2-nitrotoluene with primary and secondary alcohols at different temperatures, Journal of Solution Chemistry, 47, pp. 667-683.

[15]. Li, X.X., Fan, G.C., Zhang, Z.L., Wang, Y.W. and Lu, Y.Q., 2013, Density and viscosity for binary mixtures of diethylene glycol monobutyl ether with monoethanolamine, diethanolamine, and triethanolamine from (293.15 to 333.15) K, Journal of Chemical \& Engineering Data, 58(5), pp.1229-1235.

[16]. Patil, A.V., Pawar V.P., 2015, Dielectric Relaxation Study of Diethanolamine with Triethanolamine at Melting Points using tdr, bio nano frontier, 8 (3), pp.308-311.

[17]. Kumar. S and Jeevanandham. P, 2012, Densities, viscosities, refractive indices and excess properties of aniline and o-anisidine with 2alkoxyethanols at $303.15 \mathrm{~K}$, Journal of molecular Liquids, 174, pp.34-41.

[18]. Kinart, C.M., Klimczak, M., Cwilinska, A. and Kinart, W.J., 2007, Relative permittivity of the binary mixtures of 2-methoxyethanol with diethylene glycol, triethylene glycol, tetraethylene glycol, and polyethylene glycol 200 at various temperatures, The Journal of Chemical Thermodynamics, 39(5), pp.822-826.

[19]. Ajay, C. and NM, M., 2001, Static Dielectric Constant and Relaxation Time for the Binary Mixture of Water, Ethanol, N. NDimethylformamide, Dimethylsulphoxide, and N, M-Dimethylacetamide with 2-methoxyethanol, Bulletin of the Korean Chemical Society, 22(4), pp.357-361.

[20]. Khirade, P.W., Chaudhari, A., Shinde, J.B., Helambe, S.N. and Mehrotra, S.C., 1999, Static dielectric constant and relaxation time measurements on binary mixtures of dimethyl sulfoxide with ethanol, 2-ethoxyethanol, and propan-1-ol at 293, 303, 313, and 323 K, Journal of Chemical \& Engineering Data, 44(5), pp.879-881.

[21]. Sankar, U., Parthipan, G., Undre, P., Khirade, P.W., Thenappan, T. and Mehrotra, S.C., 2009, Interaction studies on the binary mixture of $\begin{array}{lll}\text { formamide } & \text { with }\end{array}$ 2-ethyl-1-hexanol, and isopropanol at 303 K, Main Group Chemistry, 8(2), pp.61-69.

[22]. Prajapati, A.N., Vyas, A.D., Rana, V.A., Bhatnagar, S.P., 2010, Dielectric relaxation and dispersion studies of mixtures of 1-propanol and benzonitrile in pure liquid state at radio and microwave frequencies, Journal of Molecular Liquids, 151, pp. 12-16.

[23]. Kumar, S., Guganathan, L., Malathi, M., Mohan, A., and Amalanathan, R., 2018, Dielectric Relaxation Studies of Ethyl acetate with 2Alkoxyethanols Using Time Domain Reflectometry Technique, Journal of Computational Information Systems, 14 (6), pp.18-33.

[24]. Sarode, A.V., Kumbharkhane, A.C., 2011, Study of dielectric relaxation and thermodynamic behaviour in poly(propylene glycol) using time domain reflectometry. Journal of Molecular Liquids, 160, pp. 109-113.

[25]. Sengwa, R.J., Sankhla, S., Khatri, V., 2009, Dielectric constant and molecular association in binary mixtures of N,N-dimethylethnolamine with alcohols and amides, Fluid Phase Equilibria, 285, pp.50-53.

[26]. Trivedi, C.M., Rana, V.A., Hudge, P.G. and Kumbharkhane, A.C., 2016, Dielectric relaxation studies of binary mixture of $\beta$-picoline and methanol using time domain reflectometry at different temperatures, Journal of Advanced Dielectrics, 6(03), pp.1650022.

[27]. Kumar, S. and Guganathan, L., 2018. Dielectric Relaxation studies of Butyl acetate with 2-Alkoxyethanols using Time Domain Reflectometry, Journal of Emerging technologies and innovative Research.5 (11) pp.544-554.

[28]. Kirkwood, J.G., 1939, The dielectric polarization of polar liquids. The Journal of Chemical Physics, 7(10), pp.911-919.

[29]. Kumar, S., Periyasamy, P. and Jeevanandham, P., 2012, Dielectric Relaxation Studies of Amides with 2-methoxyethanol and 2butoxyethanol Using Time Domain Reflectometry Technique, Int. J. Recent Sci. Res.3 (6), pp.420-431.

[30]. Lone, B.G., Undre, P.B., Patil, S.S., Khirade, P.W. and Mehrotra, S.C., 2008, Dielectric study of methanol-ethanol mixtures using TDR method. Journal of molecular liquids, 141(1-2), pp.47-53.

[31]. Kumbharkhane, A.C., Puranik, S.M., Akode, C.G. and Mehrotra, S.C., 2000, Dielectric relaxation studies of acetophenone-ethanol mixtures using time domain reflectometry, In Indian journal of physics and proceedings of the indian association for the cultivation of science a 74(5), pp. 471-474.

[32]. Sengwa, R.J., Sankhla, S., Khatri, V. and Choudhary, S., 2010, Static permittivity and molecular interactions in binary mixtures of ethanolamine with alcohols and amides, Fluid Phase Equilibria, 293(2), pp.137-140.

[33]. Chaudhari A., Antia D., Raju G., Chaudhari H., Prakash K., Navinkumar N., Suresh M, 2001, Proc. NatlScicounc, ROC A, 25, $205-210$. 
[34]. Kumar S., Amalanathan R., and Guganathan L., 2018. Dielectric Relaxation studies of Diethanolamine with 2-Alkoxyethanols using Time Domain Reflectometer at 303.15K. Journal of Computational Information Systems, 15 (1), pp.35-53.

[35]. Kumbharkhane, A.C., Puranik, S.M. and Mehrotra, S.C., 1992, Temperature dependent dielectric relaxation study of ethylene glycol-water mixtures, Journal of solution chemistry, 21(2), pp.201-212.

[36]. Bruggeman, V.D., 1935, Berechnung verschiedener physikalischer Konstanten von heterogenen Substanzen. I. Dielektrizitatskonstanten und Leitfahigkeiten der Mischkorper aus isotropen Substanzen, Annalen der physik, 416(7), pp.636-664.

[37]. Kumar, S., Guganathan, L., Malathi, M., Mohan, A., and Amalanathan, R., 2018, Dielectric Relaxation Studies of Methyl acetate with 2Alkoxyethanols Using Time Domain Reflectometry Technique. International Journal of Scientific Research in Physics and Applied Sciences, 6, (5), pp.27-40.

[38]. Pawar, V.P., Patil, A.R. and Mehrotra, S.C., 2005, Temperature-dependent dielectric relaxation study of chlorobenzene with nmethylformamide from $10 \mathrm{MHz}$ to $20 \mathrm{GHz}$, Journal of molecular liquids, 121(2-3), pp.88-93.

[39]. Kumbharkhane, A.C., Puranik, S.M. and Mehrotra, S.C., 1993, Dielectric relaxation studies of aqueous N,N-dimethylformamide using a picosecond time domain technique, Journal of solution chemistry, 22(3), pp.219-229.

[40]. Parthipan G. and Thenappan T., 2007, "An Investigation on the Molecular Dynamics of Binary Mixtures of Anisole with Acetic and Propionic Acids," Journal of solution chemistry, 36(10), pp. 1231-1242.

[41]. Mohan, A., Malathi, M., Shaikh, S.S. and Kumbharkhane, A.C., 2016. Thermodynamic and Molecular Dielectric Relaxation Studies of Polar-Polar Binary Mixtures Using Time Domain Reflectometry Technique, Journal of Solution Chemistry, 45(2), pp.221-234.

[42]. Redlich, O. and Kister, A.T., 1948, Algebraic representation of thermodynamic properties and the classification of solutions, Industrial \& Engineering Chemistry, 40(2), pp.345-348.

[43]. Gupta, K.K. and Bansal, A.K., 2005, Study of Molecular Interactions in Binary Mixtures of Acetophenone Derivative and Cyclohexylamine, Indian Journal of Physics, 79(1), pp.147-152.

[44]. Parthipan G; Arivazhagan G; T Thenappan; Philhos Mag Lett, (2008), 88, 125-136.

[45]. Kumar, S., Amalanathan, R., Malathi, M., Mohan, and Guganathan, L., 2018. Dielectric Relaxation studies of Monoethanolamine with 2Alkoxyethanols using Time Domain Reflectometry Technique, Journal of Emerging technologies and innovative Research,5 (11 ), pp 545555 .

[46]. Balaji, R., Sankar, M.G., Sekhar, M.C. and Shekar, M.C., 2016, FT-IR Spectroscopic study of excess thermodynamic properties of liquid mixtures containing N-methylformamide with 2-alkoxyethanols at various temperatures. Journal of Molecular Liquids, 216, pp.330-341.

\section{AUTHORS PROFILE}

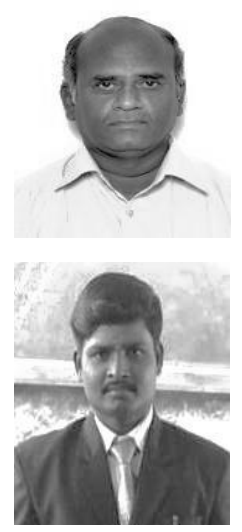

Dr. S. Kumar has completed his M.Sc (Physics), M.Phil and Ph.D in 1986, 1988 and 2001 respectivelty. He is currently working as Associate Professor in the Department of Physics, Annamalai University, Chidambaram. He has published more than 30 Papers in reputed international journals / conferences. His main research work focuses on Dielectric studies of molecular interaction in liquids. He has 30 years of teaching and research experience.

Mr. R. Amalanathan has completed his M.Sc (Physics), B.Ed., and going to submit the Ph.D thesis in 2015 and 2019 respectively. He is currently doing his Ph.D (Physics) in the Department of Physics, Annamalai University, Chidambaram. He has presented his research articles in 06 national and international Conferences and $\mathrm{He}$ has published 02 research papers in the international journals. 